\title{
A escrita no escuro: um estudo do narrador em Ontem não te vi em Babilônia, de António Lobo Antunes ${ }^{1}$
}

\author{
Paulo Ricardo Kralik Angelini
}

\begin{abstract}
Resumen: Este artículo examina Ontem não te vi em Babilônia como el fortalecimiento de la práctica, común en la literatura portuguesa contemporánea, para desestabilizar al lector a través de la polifonía de los narradores y de la metaficción.
\end{abstract}

Palabras clave: Lobo Antunes, narrador, lector, la polifonía, identidad

Resumo: Este artigo analisa Ontem não te vi em Babilônia como reforço à prática, comum na literatura portuguesa contemporânea, de desestabilizar o leitor, através da polifonia de narradores e da metaficcionalidade.

Palavras-chave: Lobo Antunes, narrador, polifonia, leitor, identidade

Que cada homem oprimido compareça diante de mim, como rei que sou da justiça. Deixai-o ler a inscrição do meu monumento. Deixai-o atentar nas minhas ponderadas palavras. (Código de Hamurábi, compilação de regras da sociedade amorita, na Babilônia)

não era nada do que escrevi até agora o que queria dizer (Ontem não te vi em Babilônia, Lobo Antunes)

Desavenças à parte, uma vez que é sabida e declarada a antipatia mútua, José Saramago e António Lobo Antunes dividem as honras de carregarem juntos um mesmo estandarte. Seguramente, são os dois mais estudados autores da literatura portuguesa contemporânea e, invariavelmente, quando a crítica sobre eles se debruça, acaba por analisar uma de suas grandes marcas: o narrador.

Lobo Antunes é conhecido por orquestrar suas vozes narrativas em um delirante jogo literário de memórias e fluxos de consciência. No entanto, essa característica polifônica nem sempre se diz presente, basta lembrar o vertiginoso discurso solitário de um homem que mergulha em suas lembranças no belo Os cus de Judas (1979), uma de suas primeiras obras.

1 Paulo Ricardo Kralik Angelini é doutor em Literatura (Letras/UFRGS), com orientação da Profa. Jane Tutikian. Atualmente é professor da Faculdade de Letras da PUCRS. 
Esses diversos narradores que se intercalam chegam, em certos romances, a um número espantoso. Em O Manual dos Inquisidores (1996), por exemplo, são dezenove. Dezenove vozes, dezenove mundos, dezenove fronteiras invadidas, dezenove pontos de vista compartilhados e estilhaçados, muitas vezes um desautorizando o outro. Sobre a artesania polifônica de Lobo Antunes, comenta o crítico Luis Mourão:

Polifonía meticulosamente trabajada, caudal metafórico controlado, cruce sutil de las historias singulares con los momentos fundamentales de la más reciente historia portuguesa, personajes que son ellos mismos siendo también la figuración posible de personajes-chave de esa misma historia reciente, todo ello envuelto en una tristeza difusa, incrustada en la piel de todas las historias y de todos los espacios, cuidad-cadena o campo-desierto, todo ello implosionando y muriendo muy lentamente mientras al fondo se vislumbra todavía una ventana abierta, una ventana iluminada. ${ }^{2}$

Escritor prolixo, habitualmente brinda seus leitores com um romance por ano. Um de seus últimos é Ontem não te vi em Babilônia, lançado em 2006 em Portugal (2008 no Brasil, Editora Alfaguara).

Durante cinco horas em plena madrugada, personagens narradores constroem, em Ontem não te vi em Babilônia, suas impressões sobre as suas vidas, "seus desânimos, as suas zangas e o que continuam a esperar"3. Cada um dos grandes seis capítulos (nomeados com a hora da ação, com o tempo da história narrada, da meia-noite até as cinco horas da manhã) é dividido em quatro capítulos menores, nos quais há, algumas vezes, uma redivisão das vozes narrativas, com interferência de um outro narrador sobre o original daquele capítulo. Nesta obra, Antunes segue a sua cartilha de seus narradores sempre em ebulição, mas avança em diferentes aspectos. O fio narrativo é tênue: o suicídio de uma menina de quinze anos, no quintal de sua casa. Diz a mãe: "a minha filha se matou aos quinze anos minha senhora, ao descer os degraus a boneca no chão, o banco, de início não vi a corda e nem me passou pela cabeça que uma corda, para que uma corda, vi a borboleta, a boneca no chão e o banco"4. Diferentes narradores referem-se a essa trágica lembrança, mas ela nunca deixa de ser embaçada, nunca é de todo clarificada. Diz a figura paterna ${ }^{5}$, o homem de Évora: "dei-lhe a boneca numa embalagem com um laço e afastei-me o mais depressa que pude antes que agradecesse, nunca a beijei e nem dei a entender que consentia beijos" ${ }^{6}$. Personagens também embaçados, frios, que se emaranham na jornada de suas palavras, à procura de identidade. Muitos nem nome possuem: "serei eu a única personagem com nome neste livro?" . Vozes que se misturam e que se afirmam num romance nervoso, tipicamente moderno, quando a reflexão vem, muitas vezes, fragmentada e ecoada em uma apreensão nem sempre exata do tempo e do espaço: "que horas serão neste momento?" . Como afirma Fernando Pinto do Amaral:

\footnotetext{
2 MOURÃO, Luis. "Narrativa contemporánea posterior a la Revolución de los Claveles". In: GAVILANES, José Luis e APOLINÁRIO, António (Orgs.). Historia de la Literatura Portuguesa. Madrid: Cátedra, 2000. p. 674

3 ANTUNES, Lobo. Ontem não te vi em Babilônia. Lisboa: Dom Quixote, 2006. p.115

4 Ibidem. p. 24

5 Por ele mesmo desmentida: "ou como se a minha filha (não tenho filhos)" (Ibidem, p. 403)

6 ANTUNES, Lobo. Ontem não te vi em Babilônia. Lisboa: Dom Quixote, 2006. p. 34

7 Ibidem. p. 89

8 Ibidem. p. 105
} 
Narrados por diversas vozes e entrecortados por fragmentos de diálogos que afloram ao discurso e se cruzam num ágil caleidoscópio de constantes flashbacks subjetivos, recuperando as coisas absurdas que se fixam na memória, os livros de Lobo Antunes conseguem levar muito longe a confusa percepção dos tempos e a translúcida projeção das lembranças, como se alguns gestos do presente pudessem magicamente transformar-se em experiências vividas no passado. ${ }^{9}$

Essa confusa percepção (seria óbvio trazer as vozes que não se compreendem na referência a Babel?) auxilia na construção de um romance de incertezas. Em Ontem não te vi em Babilônia são muito comuns as correções de registro. Há várias passagens que retificam o já dito: "não estou a ser correto, julgo que existiu um amigo, falarei nele mais à frente se me apetecer falar. E voltando ao início deve ser meia-noite porque os ruídos cessaram..." " ${ }^{10}$; “... e detestei-o por isso (não detestei, desprezei-o)" "11; "não liguem, troquei tudo, o meu pai à secretária sem um relance sequer"12; "e no entanto e no entanto uma ova, lá estou eu a deixar-me ir..." (Ibidem, p. 110); "escrevi que não a visitei nunca e mentira, fui espreitá-la num domingo" "13; "o verdadeiro de que não podes falar e de que não te dás conta, aqueles que escreveste nestas páginas escuros inventados, presunções, fantasias e afinal aí o tens"14. Mesmo a descrição de personagens pode ser equivocada: "mas sem senhoras de azul (escrevi verde antes de corrigir para azul e não sei porquê, saiu-me, háde haver uma parte da cabeça desejosa de trair-nos) $)^{15}$, até o narrador assumir que tal fato não tem importância: "uma senhora de azul ou de verde" 16 . Sugere que esse interlocutor substitua certas palavras enquanto ouve-escreve: "uma espécie de desilusão, palavra errada, emenda quando fores ler o que escreves" "17; "com o escovilhão ou a vassoura, julgo que melhor a vassoura, fica a vassoura, não tenho tempo de escolher"18.

As imprecisões de Ontem não te vi em Babilônia surgem como reforço à prática, comum na literatura portuguesa contemporânea, de desestabilizar o leitor. O que é conferido não faz parte de um terreno seguro no campo ficcional. Os relatos são marcados por supostas invenções: "lembro-me de episódios dispersos se calhar inventados"19; dúvidas: "e felizmente (porque escrevi felizmente?) ${ }^{20}$; indeterminações temporais: "há anos (sete, três, nove?)"21 ; lacunas na memória: "(não me recordo do que escrevi e não me recordo da cor)"22; incertezas da norma culta: "(ia escrever com h, hinimigo, as traiçõezinhas do cérebro, sorri para mim mesma, corrigi, continuo)"23; impossibilidade da palavra substituir a vida: "como se fosse possível conhecer alguém entre manchas (...), tudo para daqui a cinco

9 AMARAL, Fernando Pinto do. "Narrativa". In: MARTINHO, Fernando J. B. (Org.). Literatura Portuguesa do Século XX. Lisboa: Instituto Camões, 2004. p. 84

10 ANTUNES, Lobo. Ontem não te vi em Babilônia. Lisboa: Dom Quixote, 2006. p. 43

11 Ibidem.p. 76

12 Ibidem. p. 98

13 Ibidem. p. 195

14 Ibidem. p. 205

15 Ibidem. p. 128

16 Ibidem. p. 131

17 Ibidem. p. 167

18 Ibidem. p. 232

19 Ibidem. p. 118

20 Ibidem. p. 155

21 Ibidem. p. 136

22 Ibidem. p. 156

23 Ibidem. p. 440 
ou seis páginas escritas a custo, emendadas, riscadas, copiadas"24; mentiras assumidas: "a única pessoa que para mim (estou a mentir o que se passa comigo?)"25.

No capítulo "Mundo do texto e mundo do leitor", de Tempo e Narrativa, Paul Ricoeur recupera importantes conceitos discutidos por Wayne Booth (em A Retórica da Ficção) no que tange à não confiabilidade do narrador. Para o crítico francês, a literatura contemporânea exige um leitor diferenciado, preparado para o veneno dos narradores modernos: "Não se pode contestar que a literatura moderna seja perigosa. A única resposta digna da crítica que ela provoca, e da qual Wayne Booth é um dos representantes mais estimáveis, é a de que essa literatura venenosa requer um novo tipo de leitor: um leitor que responde" 26 .

Este leitor é chamado para dentro do texto. Há, na obra de Lobo Antunes, um desfilar de narradores que se dirigem a interlocutores diferentes (leitores?) "senhor major, sou sincero consigo, não lhe oculto nada"27, "não se aflija senhora"28, "meia-noite e desperta, expliquem-me o que se passa comigo" 29 . De fato, os narradores de Ontem não te vi em Babilônia frequentemente pedem ajuda ao interlocutor, buscam um socorro inexistente: "Francamente não sei o que se passa comigo ajudem-me"30. Além disso, o processo metaficcional é instaurado, seja na negação da técnica de flashback: "Não me obriguem a recapitular os invernos, a boina do meu tio lá fora e um cachorro" 31 , seja na descrição de uma cena: "Percebe a cena, não?"32, seja na afirmação do material polifônico: "não sei falar como os outros falam no livro, à vez ou todos ao mesmo tempo dado que há alturas em que me parece que todos ao mesmo tempo embora julguem que à vez"33. Nesta conversa, recados raivosos: "Não tenho muito mais a acrescentar a não ser que vos odeio a todos: desejo do fundo do coração que a vossa alma se consuma no Inferno". ${ }^{34}$

Artimanha muito comum em algumas obras de autores portugueses contemporâneos (Maria Velho da Costa, Rodrigo Guedes de Carvalho, Mário de Carvalho, citam-se apenas três entre vários) é a troca de narradores, muitas vezes dentro de um mesmo parágrafo. Por isso, Ontem não te vi em Babilônia exige um leitor atento. No quarto capítulo, por exemplo, as vozes intercalam-se, ambas em primeira pessoa. Contudo, há ao menos uma passagem na qual a troca é avisada: “entrega-se outra vez a narração à Ana Emília, já está" 35 . Há outras, bem verdade, em que não há aviso prévio, apenas a troca do narrador em meio ao narrado.

24 Ibidem. p. 431

25 Ibidem. p. 56

26 RICOEUR, Paul. "Mundo do texto e mundo do leitor". In: _. Tempo e Narrativa. Campinas: Papirus, 1997. p. 282. O texto, para Paul Ricoeur, abre-se para o seu externo, para aquilo que está fora dele, ou seja, para o mundo do leitor: "só na leitura o dinamismo de configuração encerra o seu percurso" (Ibidem, p.275). A leitura da ficção é, portanto, a intersecção entre esses mundos, "o confronto entre dois mundos, o mundo fictício e o mundo real do leitor. O fenômeno da leitura torna-se, com isso, o mediador necessário da refiguração" (Ibidem, p.276). Para Ricoeur, a persuasão é fundamental para a construção do processo da leitura. $\mathrm{O}$ autor desenvolve técnicas para seduzir o leitor que, por sua vez, ao ser persuadido, acaba apropriando-se do mundo proposto pelo texto. Por isso que, assim como Wayne Booth, Ricoeur salienta a "retórica" como organismo essencial, pois ela "rege a arte pela qual o orador visa persuadir seu auditório" (Ibidem, p.277).

27 ANTUNES, Lobo. Op. Cit. p. 412

28 Ibidem. p. 144

29 Ibidem. p. 55

30 Ibidem. p. 50

31 Ibidem. p. 53

32 Ibidem. p. 99

33 Ibidem. p. 115

34 Ibidem. p. 400

35 Ibidem. p. 180 
Esses narradores assumem o processo da escrita, antecipando futuros leitores: "E agora, pergunto, o que será de mim quando acabado este capítulo deixarem para sempre de me ouvir, quem se lembrará do que fui [...] ninguém se lembra, pensa, se preocupa, compram outros livros, esquecem-me e eu sozinha em páginas sem leitor algum"’36; contudo, muitas vezes um narrador contradiz o outro, procurando esboçar uma leve discussão ficcional X real: "Repito que isto não é um livro, aconteceu assim"37, mas, posteriormente, novamente o embaralhar de vozes contraditórias: "a acabar este livro que não é um livro, é a vida, um indicador numa fotografia" ${ }^{38}$. A personagem narradora questiona-se se ela própria não seria criação: "Pergunto-me se inventei tudo ou estarão a inventar-me a escreverem a custo, a emendar, a riscar, a escreverem de novo, a passarem a limpo e ao ler" ${ }^{\prime 3}$. Cientes do processo da leitura, indagam quem seriam seus leitores: "Quem vai ler isto, senhores?" Porém, a narrativa metaficcional de Antunes vai mais longe. Irônica e contraditoriamente, Ontem não te vi em Babilônia, uma das obras mais esvaziadas de traços autobiográficos, apontados, por exemplo, em Os cus de Judas, traz a assinatura do autor empírico. Em meio a tantas vozes e discursos, surge o seguinte comentário: "Chamo-me António Lobo Antunes, nasci em São Sebastião da Pedreira e ando a escrever um livro" "41. É a inclusão solitária do autor empírico na rede de narradores do romance.

Interessante apontar que, evidentemente, o nome do autor inserido na narrativa causa um certo impacto junto ao leitor. Uma estranheza. Como diz Helena Buescu, recuperando tal artimanha desenvolvida em demasia por Camilo Castelo Branco: "Os nomes dos autores, em meados do século XIX, fazem parte do processo de comunicação literária, têm efeitos sociais e efeitos simbólicos" ${ }^{42}$. Tal fato é, atualmente, intensificado na literatura contemporânea do século XXI, pois “o autor não esconde, pelo contrário exibe, em gesto muito camiliano, a sua identidade civil e empírica” (Ibidem, p. 52).

A estratégia pesca o leitor descuidado, que pode não perceber a sedução do canto da sereia: o narrador que se revela, disfarçando-se no autor empírico ${ }^{43}$. Há muitos escritores que se apropriam dessa técnica, como Helder Macedo, que comenta: “O disfarce autoral serve para solicitar a cumplicidade do leitor, que acompanha o escritor no próprio processo da escrita. Uma piscadela de parte a parte" 44 . Macedo ressalta, ainda, esse dinamismo entre categorias tidas como estanques para muitos teóricos:

Procuro de algum modo forjar qualquer coisa que permita um trânsito dinâmico, espero eu, entre várias categorias. Porque não se pode levar muito a sério o autor

36 Ibidem. p. 421

37 Ibidem. p 435

38 Ibidem. p. 473

39 Ibidem. p. 439

40 Ibidem. p. 469

41 Ibidem. p. 465

42 BUESCU, Helena Carvalhão. Em busca do autor perdido: histórias, concepções, teorias. Lisboa: Cosmos, 1998. p. 57

43 Ficção é persuasão, e o autor implicado está na origem da estratégia dessa persuasão, cujo alvo é o leitor. O autor implicado, esse ser literário criado na e a partir da leitura, não é, segundo Ricoeur, simetricamente o oposto do leitor implicado. A diferença se faz na própria representação de cada um: "enquanto o autor real se apaga no autor implicado, o leitor implicado ganha corpo no leitor real” (Ibidem, p.292). Ou ainda: enquanto o autor implicado é uma máscara do real, o leitor real é a concretização do implicado, desse leitor possível que se instaura também dentro do texto.

44 __ Identidade portuguesa não existe. Jornal do Brasil - JB Online, Rio de Janeiro, 3 ago. 2002. Disponível em: http://jbonline.terra.com.br/jb/papel/cadernos/ideias/2002/08/02/joride20020802008.html. Acesso em 30 de novembro de 2002. Entrevista concedida a Evandro Teixeira. 
onisciente que está de fora. Não está de fora! As personagens dialogam, dizem coisas, e acontece a todos os romancistas - alguns que se confessam como eu, outros que não - a certa altura as personagens dizerem: 'Eu isso não faço, recuso-me!' E temos que lidar com isso. ${ }^{45}$

Em Ontem não te vi em Babilônia, este processo não aparece acentuado; é um caso isolado. O que é, sim, vertiginosamente trabalhado é o estilismo. Os aspectos formais, marca desde sempre de Lobo Antunes, causam uma certa perturbação estilística. Pontuação e sintaxe extravagantes: "se caísse na asneira de entrar no meu quarto tu um gato preto morto na cama" 46 , falta de letra maiúscula no início de frase "chamo-me Alice meu Deus, não permitais que as chamas do Inferno" ${ }^{47}$, palavras agrupadas, a convenção ortográfica acompanhando a urgência do discurso: "Jogueiodaescarpaparaaquallançarumacordadeto alha"48, palavras incompletas: "você a imp, a impedir-me de sofrer"49, o frequente uso de parênteses "tentando resumir (adeus Marionela)" ", as interrupções do discurso, que se mantém em suspenso, por vezes posteriormente recuperado:

"a dentadura postiça no chão, não uma dentadura completa, alguns dentes, o lábio (...) ia no lábio, pus o mindinho na palavra lábio, o lábio" 51

São essas todas marcas que provocam uma sensação caótica, de desorganização formal, mas que se estruturam muito a partir da própria percepção do pensamento humano: "o que é a memória santo Deus, zonas até então ocultas à mostra com que intenção, que motivo" 52 . Pensamentos confusos, que vêm e vão, entram em contato com outros e de dissipam, num complexo jogo de associação de ideias:

camas sem colchão nas quais não se imagina que pessoas um dia, eu dantes em bicos de pés para alcançar a fruteira com as uvas de cerâmica cujo rebordo sempre conheci partido e hoje as frutas insignificantes, modestas, o que fui sem importância, o que passou sem interesse, que ridículo Lurdinhas, a minha colega

— Vão esquecer-me vocês

e eu já esquecida senhores, se me virem uma careta à procura ${ }^{53}$

Na construção dessas vozes que atravessam a madrugada, há o processo da repetição: "deve ser meia-noite porque os ruídos cessaram" 54 , ecoado em "deve ser meia noite porque os cachorros desistem" 55 . Ou a seguinte passagem: "não era nada do que escrevi que eu queria dizer", que aparece nas páginas $315,316,326$ e 330.

45 MACEDO, Helder. É quase milagroso que Portugal seja um país normal. Lisboa, 21 mar. 1998. Jornal Público, Lisboa. Disponível em: http://www.instituto-camoes.pt/arquivos/literatura/arqvhmacedo.htm. Acesso em 15 de outubro de 2006. Entrevista concedida a Mário Santos.

46 ANTUNES, Lobo. Op. Cit. p. 101)

47 Ibidem. p. 61

48 Ibidem. p. 388

49 Ibidem. p. 417

50 Ibidem. p. 265

51 Ibidem. p. 301

52 Ibidem. p. 474

53 Ibidem. p. 139

54 Ibidem, p. 31

55 Ibidem. p. 32 
Há diálogos, inclusive, que se constroem totalmente em cima de repetições:

- Se me deixassem contar-te

o estranho não

- Se me deixassem contar-te

cerimonioso, educado, o estranho é evidente

- Se me deixassem contar-lhe madame ${ }^{56}$

Quando indagado sobre seu processo de criação, Lobo Antunes certa vez disse que seus personagens iluminam-se uns aos outros, sublinhando contradições. Em Ontem não te vi em Babilônia, de fato, é quase o contrário, como se os personagens apagassem uns aos outros, tirando-lhes a luz, tornando-os cada vez mais opacos.

São seres solitários à procura de um ouvinte: "Escuta"57; seres decadentes: "quase cinquenta e sete, estou velha, não me farejam nem se me agitam em torno, deixam-me em sossego a carregar o ventre morto" 58 ; seres sem afeto, carentes: "por favor, toquem-me, sintam-me" 59 ; seres inertes: "falta-me esperança e músculos, uma vontade de chegar que me corrija o desânimo"600; seres medíocres: "não sou uma pessoa interessante, não me aconteceram coisas interessantes na vida" ${ }^{\prime}$; seres animalizados: "tento levantar-me e as minhas patas incapazes de caminharem" "62; seres perdidos no tempo: "que dia é hoje, terçafeira, sexta, vinte e um, cinco, dezenove e qual o mês, qual o ano" "33; seres atormentados: "deviam chover lágrimas quando o coração pesa muito e há momentos, palavra de honra, não se compreende o motivo mas pesa, sente-se dentro o" ${ }^{" 64}$, que gritam suas dores, escrevem mesmo sem palavras: "porque aquilo que escrevo pode ler-se no escuro" ${ }^{65}$. Porque é do escuro que são feitos. Porque, nessa tristeza difusa, à espera sempre estarão: "Porque continuam a esperar embora afirmem que não"66.

Jogo de culpas centralizadas em um suicídio: "Escrevo o fim deste livro em nome da minha filha que não pode escrever, às vezes penso que ainda à espera no quarto"67, código particular de Hamurábi recuperado por sujeitos em uma torre de incomunicabilidade: personagens babilônicos, oriundos de uma terra perdida no tempo e no espaço, uma nação grande que se apequenou, sem solo, sem alma, sem vida.

“(elas incapazes de uma letra e eu sem tempo de escrever, passa das cinco da manhã, o fim do livro e é tudo)" ${ }^{\prime 68}$.

\section{Referências}

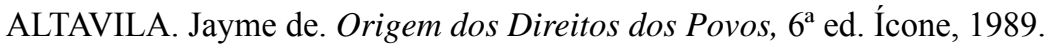

56 Ibidem. p. 188

57 Ibidem. p. 19

58 Ibidem. p. 47

59 Ibidem. p. 50

60 Ibidem. p. 455

61 Ibidem. p. 115

62 Ibidem. p. 167

63 Ibidem. p. 358

64 Ibidem. p. 358

65 Ibidem. p. 479

66 Ibidem. p. 115

67 Ibidem. p. 459

68 Ibidem. p. 469 


\section{Conexão Letras}

AMARAL, Fernando Pinto do. "Narrativa". In: MARTINHO, Fernando J. B. (Org.). Literatura Portuguesa do Século XX. Lisboa: Instituto Camões, 2004.

ANGELINI, Paulo Ricardo Kralik. Capelas Imperfeitas: o narrador na construção da literatura portuguesa do século XXI. Tese de doutorado. Porto Alegre: UFRGS, dezembro de 2008.

ANTUNES, Lobo. O manual dos inquisidores. Rio de Janeiro: Editora Rocco, 1998.

. Ontem não te vi em Babilônia. Lisboa: Dom Quixote, 2006.

Os cus de Judas. Lisboa: Dom Quixote, 2001.

BOOTH, Wayne. A retórica da ficção. Lisboa: Arcádia, 1980.

BUESCU, Helena Carvalhão. Em busca do autor perdido: histórias, concepções, teorias. Lisboa: Cosmos, 1998.

MACEDO, Helder. É quase milagroso que Portugal seja um país normal. Lisboa, 21 mar. 1998. Jornal Público, Lisboa. Disponível em: http:/www.instituto-camoes.pt/arquivos/ literatura/arqvhmacedo.htm. Acesso em 15 de outubro de 2006. Entrevista concedida a Mário Santos.

Identidade portuguesa não existe. Jornal do Brasil - JB Online, Rio de Janeiro, 3 ago. 2002. Disponível em:

http://jbonline.terra.com.br/jb/papel/cadernos/ideias/2002/08/02/joride20020802008. html.

Acesso em 30 de novembro de 2002. Entrevista concedida a Evandro Teixeira.

MOURÃO, Luis. "Narrativa contemporánea posterior a la Revolución de los Claveles". In: GAVILANES, José Luis e APOLINÁRIO, António (Orgs.). Historia de la Literatura Portuguesa. Madrid: Cátedra, 2000.

RICOEUR, Paul. "Mundo do texto e mundo do leitor". In: . Tempo e Narrativa. Campinas: Papirus, 1997. 